\title{
Two vortex interaction patterns in a turbine rotor
}

\author{
Jerzy Świrydczuk, Assoc. Prof. \\ Institute of Fluid-Flow Machinery, Gdansk
}

\begin{abstract}

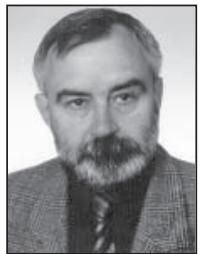

The article analyses the unsteady interaction of vortex structures in a turbine rotor passage. In the form of sample cases, two high-pressure steam turbine stages are examined: a standard stage, used as the reference, which reveals regular performance characteristics and distributions of flow parameters, and a low-efficiency stage, in which a large separation zone is observed in the rear part of the rotor passage. In the latter case the combined interaction of all vortices has been found to take an extremely complex course and be a source of remarkable flow fluctuations. The methodology applied for extracting particular vortex structures from the general flow pattern bases on comparing entropy distributions with corresponding velocity vectors. The reported vortex interaction patterns are believed to be representative for a variety of turbine constructions of both land, and marine applications.
\end{abstract}

Keywords: secondary vortices; turbine rotor; interaction pattern

\section{INTRODUCTION}

The flow through a turbine stage, even treated as an isolated machine, is extremely complex due to the presence of numerous secondary flows and vortex structures in the stator and rotor cascades. Firstly, horseshoe vortices are formed at leading edges of the stator and rotor blades, near hub and tip endwalls. Inside the rotor passage these vortices are believed to be incorporated as part of passage vortices forming due to the action of passage cross flows. At the same time, the trailing edges of the stator and rotor blades are the sources of wakes moving downstream with the main flow into the next cascades. Also flow separations, occasionally observed at rotor passages, can frequently lead to the creation of additional large-scale vortices of various orientations. Permanent interactions between all the abovementioned main flow structures, not mentioning those of smaller or varying intensity, such as corner or leakage vortices for instance, make studying the turbine flow extremely difficult. Various secondary flow models developed to illustrate the flow structure inside the stator/rotor passage differ in many details with respect to relative positions of the vortices with respect to each other and passage walls [1-3].

Theoretically, Computational Fluid Dynamics (CFD) codes developed for solving Navier-Stokes equations provide opportunities for taking into account all details of the above interactions. In practice, however, economic and technical limitations make the CFD code user look for a reasonable compromise between the expected accuracy of the results to be obtained and the time necessary for performing those calculations. Of high importance here is the grid resolution, a parameter which highly affects both the computation time and credibility of the obtained results. A question what grid resolution secures obtaining grid independent results of vortex interaction in a turbine rotor passage has not been answered satisfactorily yet. Some estimations place this limit at the level of about 2000000 nodes per stator/rotor passage [4], but opinions can also be found in the literature that a grid finer by an order in magnitude is necessary for this purpose [5].

The present article discusses unsteady interactions of vortex structures in a turbine rotor, including the formation and development of horseshoe vortices, passage vortices, stator and rotor wakes, and separation structures. The interaction process is examined in stages revealing different performance characteristics, with a general aim to collect a variety of possible courses of vortex interactions and assess the scale of their effect on overall stage performance. In those stages the flow structure is analysed by comparing flow patterns obtained in steady-state and fully unsteady conditions.

\section{STAGE GEOMETRY AND FLOW CONDITIONS}

Two steam turbine stages were selected for the examination based on preliminary steady-state results recorded on a moderate-resolution grid of an order of 300000 cells per stator/rotor passage. The design of the both stages is basically the same, see Fig. 1. 


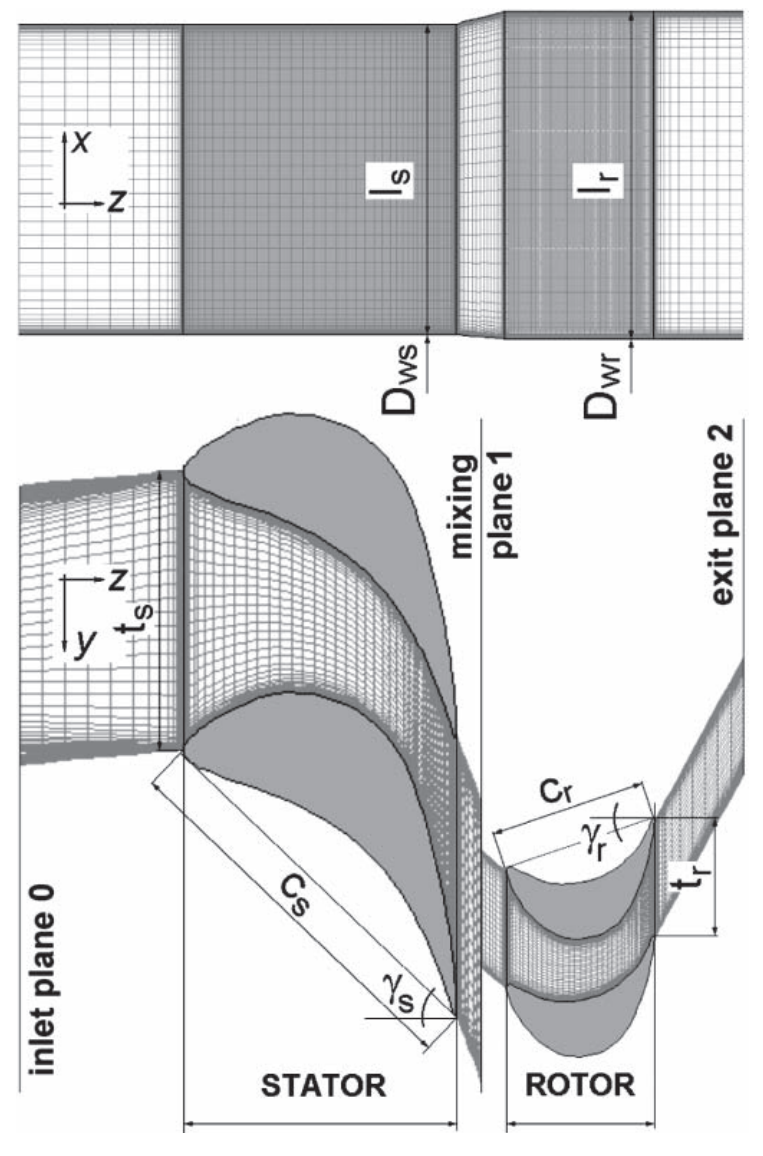

Fig. 1. Turbine stage geometry

The inner diameters of the stator and rotor passages, $\mathrm{D}_{\text {ws }}$ and $\mathrm{D}_{\mathrm{wr}}$, are equal to 812 and $810 \mathrm{~mm}$, respectively, while the stator and rotor blade lengths, $1_{\mathrm{s}}$ and $1_{\mathrm{r}}$, are equal to 60 and 64 $\mathrm{mm}$. The stator-to-rotor pitch ratio $\mathrm{t}_{\mathrm{s}} / \mathrm{t}$, is equal to 2.36 . The stator and rotor cascades are composed of PLK and P2 blade profiles. The chord of the stator blades, $\mathrm{c}_{\mathrm{s}}$, is equal to $75 \mathrm{~mm}$, and their stagger angle, $\gamma$, is equal to 44 degrees. The first stage, referred to as the reference stage (REF) in the article, is a real high pressure turbine stage, which reveals relatively good performance characteristics and regular distributions of losses. The second stage (LES), in turn, presents visibly decreased efficiency, and untypical and varying stage loss distributions, see Fig. 2. Unlike the regular distributions in which only increased losses near the hub and tip endwalls are observed, the loss distributions recorded in the LES stage frequently revealed additional huge maxima near the rotor passage midspan sections. Rough analysis of entropy distributions recorded in relevant $\mathrm{x} 0 \mathrm{y}$ rotor sections suggested massive flow separation in this region.

A basic tool used for examining the vortex interaction was FlowER, a specialised CFD code developed for studying flows through turbine stages and sections. In the here reported application the code solved a set of Unsteady Reynolds Averaged Navier-Stokes (URANS) equations complemented by Menter's SST turbulence model. A detailed description of the code and its characteristics was given by Yershov et al [6]. In the past, the code was frequently used by IF-FM research teams for studying flows through turbine stages and sections. The results of these studies were, as a rule, in more than good agreement with the measurement data recorded on both model turbines and real turbosets in operation in Polish power plants. It is noteworthy that this good agreement referred not only to overall turbine performance parameters such as efficiency, mass flow rate, etc, but also to local distributions of flow parameters such as pressures, velocities and flow angles [7-8]. As far as unsteady vortex interactions are concerned, direct code validation was not performed due to the lack of relevant reference data. However, FlowER was used by the author in the past for studying the 2D flow structure in a HP turbine rotor passage [9]. In that study the pattern of stator wake development in the rotor passage was analysed by comparing the results obtained from FlowER with those given by the vortex dynamics theory, which, in turn, had been validated using the results recorded by Kost on a model turbine [10]. This study is a continuation and $3 \mathrm{D}$ extension of that presented in 2002.

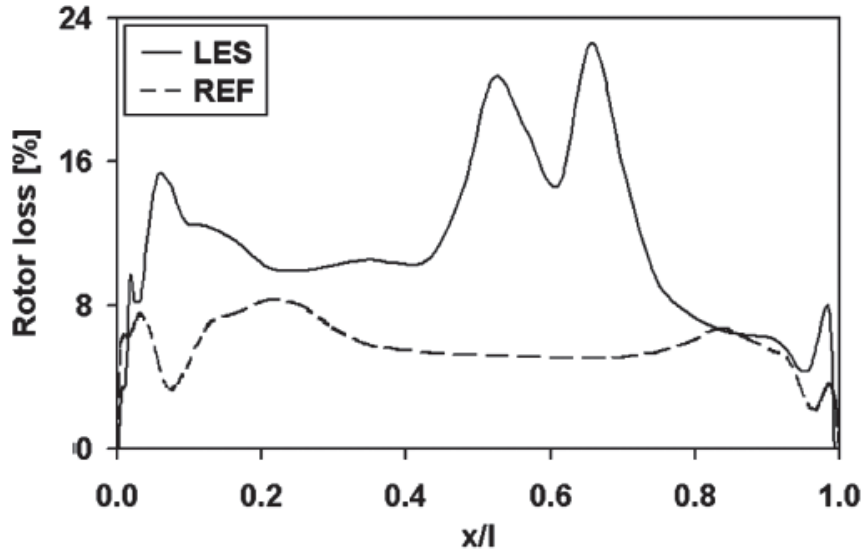

Fig. 2. Spanwise distributions of rotor losses recorded downstream of the rotor blade trailing edge in REF and LES stage

The flow conditions assumed in the present study included the steam pressure drop, $\mathrm{p}_{2}-\mathrm{p}_{0}$, from 79 to 71 bars, and inlet total temperature, $\mathrm{T}$, equal to $746.3 \mathrm{~K}$. The steam flow direction at stage inlet was assumed axial. The resultant averaged mass flow rates, calculated for these conditions, were equal to $158.3 \mathrm{~kg} / \mathrm{s}$ for the REF stage and $172.7 \mathrm{~kg} / \mathrm{s}$ for the LES stage. The circumferential forces and torques generated by the flow in the LES rotor were by $7 \%$ larger than those recorded in the REF stage. The relative mass averaged Mach numbers at rotor inlet were equal to 0.147 and 0.180 , respectively, in the REF and LES stage.

The calculations were performed on an H-type grid. Grid parameters for detailed investigations were selected based on the analysis of preliminary steady-state calculations performed on a series of grids with increasing resolution. Following recommendations formulated in past analyses [4], the selected grid had $144 \times 120 \times 116=2004480$ nodes in one stator passage and $144 \times 64 \times 240=2211840$ nodes in one rotor passage. Refined grid resolution in the main flow area was occupied by slightly decreased resolution in the boundary layers, which was a compromise made with an intention to provide comparable conditions for vortex development in the entire flow area. The $y+$ values obtained at the rotor walls as a result of the above compromise were approximately equal to 25 . The three-level multigrid procedure was used in the calculations, with 50000 iterations performed on the first level and 50000 on the second level. The third-level calculations were continued until iteration 200 000, after which an acceptable regular shape of the force time history was obtained, see Fig. 3. The number of iterations covering one time period $\mathrm{T}$ of the relative rotor/stator motion, here understood as the time after which the next stator blade takes the position occupied by the previous one with respect to the rotor blade, was automatically calculated by the code based on the selected dimension of the smallest cell. In the present calculations this number was slightly less than 5000 , which means that the regular shape of the force time-history was obtained after over 40 periods. 


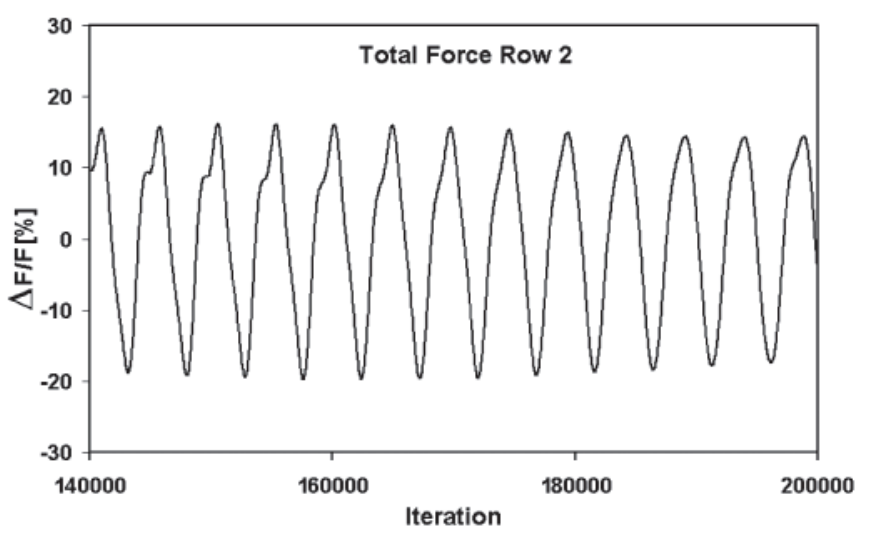

Fig. 3. Time-history of total force fluctuations in turbine rotor

\section{STATOR WAKE AT ROTOR INLET}

The examined stages are impulse stages. In those stages the major part of steam expansion is realised in the stator, and the main role of the rotor cascade is to reverse the flow. As a result, the flow changes its direction by less than 80 degrees (from axial to nearly circumferential) in the stator, and by as much as about 140 degrees in the rotor cascade. Since the intensities of secondary flow structures in turbine cascades are commonly believed to be in close relation with the above flow angle differences, much more intensive structures are expected to be recorded in the rotor.

Fig. 4 shows two selected instantaneous entropy distributions recorded inside and in front of the rotor cascade. The diagram on the left presents a typical flow pattern recorded at the rotor passage half-span section, with stator and rotor wakes being the only secondary flow structures. The flow pattern on the right was recorded at the rotor inlet, at a distance of $0.1 \mathrm{c}_{\mathrm{rz}}$ ( $\mathrm{c}_{\mathrm{rz}}$ - rotor blade chord projection onto the turbine axis) from rotor blade leading edges, when the stator wake occupied an approximate position in the middle between the rotor blades. The stator wake shown here is slightly inclined with respect to the radial direction, and has a regular shape along most of its length. Only near the endwalls, at an approximate distance of $0.051_{r}\left(1_{r}\right.$ - rotor blade length) from the hub endwall, and about $0.15 \mathrm{l}_{\mathrm{r}}^{\mathrm{r}}$ from the tip endwall $15 \%$, some traces of stator passage vortices can be noticed.

To check the relations between intensities of particular vortex structures observed at rotor inlet, a series of diagrams showing velocity distributions along selected $y$-lines located in the plane $\mathrm{z} / \mathrm{c}_{\mathrm{rz}}=-0.1$ at different $\mathrm{x} / \mathrm{l}_{\mathrm{r}}$ values has been prepared, see Fig. 5. Different axis orientations of the vortex structures shown in the plane $\mathrm{z} / \mathrm{c}_{\mathrm{rz}}=-0.1$ do not provide opportunities for selecting one leading velocity component and treat it as the representative material for studying vortex behaviour. That is why all three velocity components are presented in Fig. 5. The curves in each diagram compose two series, one of which represents the time instant of the current wake position shown in Fig. 4, while the other - their values averaged over the entire time period of relative stator/rotor motion. The observed differences between these curves are expected to reflect the effects generated by the vortex structures. Two continuousline curves: the thick curve recorded at the time instant from Fig. 4 at the half-span section $\left(\mathrm{x} / \mathrm{l}_{\mathrm{r}}=0.50\right)$ and its thinner equivalent representing the averaged distribution, are given as the reference to illustrate velocity changes generated by the stator wake alone. Three remaining curves were been recorded at the characteristic sections: $\mathrm{x} / \mathrm{l}_{\mathrm{r}}=0.05$ - stator hub passage vortex location, $\mathrm{x} / \mathrm{l}_{\mathrm{r}}=0.87$ - stator tip passage vortex location, $\mathrm{x} / \mathrm{l}_{\mathrm{r}}=0.95$ - no visible presence of any regular structures.

\section{Entropy}

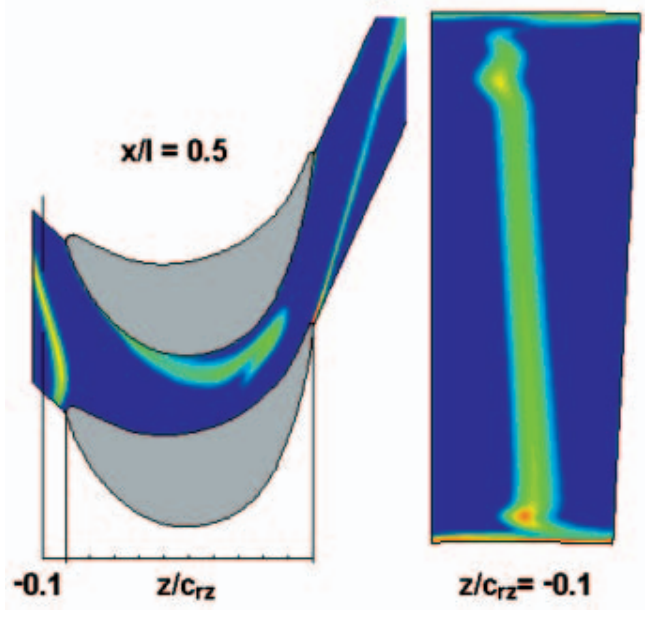

Fig. 4. Stator wake patterns in $y 0 z$ and $x 0 y$ planes inside and in front of rotor passage

Analysing the REF curves $\left(\mathrm{x} /{ }_{1 \mathrm{r}}=0.50\right)$ in the left-hand diagram leads to the conclusion that the action of the stator wake manifests itself in the presence of a disturbance having a sinusoidal shape. Starting from the left, the instantaneous velocity first increases above the averaged values, then decreases below and finally reaches again the level higher than the averaged curve. Disturbances of similar nature can be recognised in all remaining instant curves, the only difference being relative
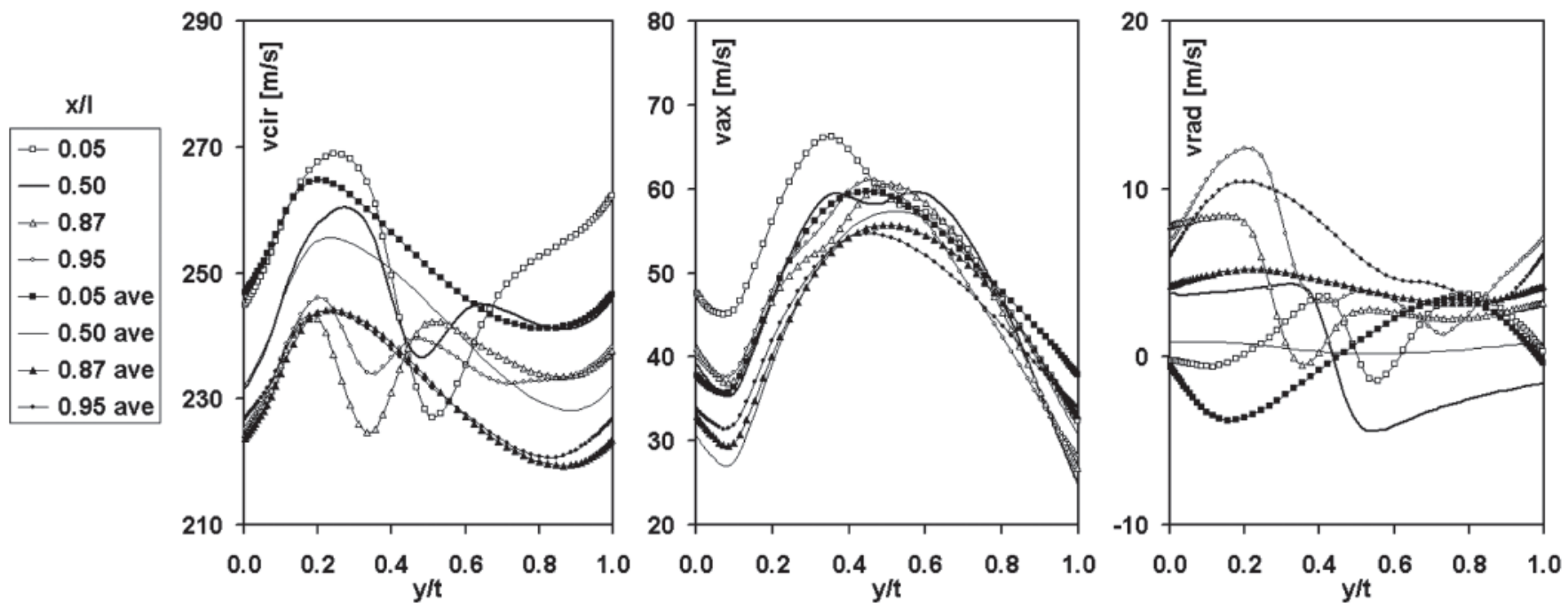

Fig. 5. Distributions of velocity components in plane $z / c_{r z}=-0.1$ : left - circumferential velocity, centre - axial velocity, right - radial velocity 
levels of particular maximum points, see the curve $\mathrm{x} / 1=0.87$ for instance. All this suggests that most of unsteady effects are generated by the stator wake, to which other vortices contribute in minor part. In the central diagram, the instant REF curve reveals a weak local minimum situated between two maxima. Other curves do not, in general, reveal remarkable disturbances, except the curve $\mathrm{x} / \mathrm{1}_{\mathrm{r}}=0.05$, the left-hand part of which reaches visibly higher maximum than the remaining curves. This effect seems to be provoked by the action of the hub stator passage vortex. A similar effect, but to a much smaller degree and opposite in direction, can be noticed on the curve $\mathrm{x} / \mathrm{l}=0.87$ the left-hand part of which reveals slight deflection. In the third diagram, the stator wake provoked disturbances have a form of rapid velocity drop, from the left to the right. When observed in other instant curves, this effect is sometimes followed by a velocity rise, especially visible on the curve $\mathrm{x} / 1_{\mathrm{r}}=0.05$.

Based on the above analysis, it is the stator wake which seems to be most intensive and generates most remarkable disturbances at the rotor inlet, while the disturbances provoked by the stator passage vortices are clearly less intensive. The above flow characteristics at the rotor inlet, $\mathrm{z} / \mathrm{c}_{\mathrm{rz}}=-0.10$, is representative for both the REF stage and the LES stage.
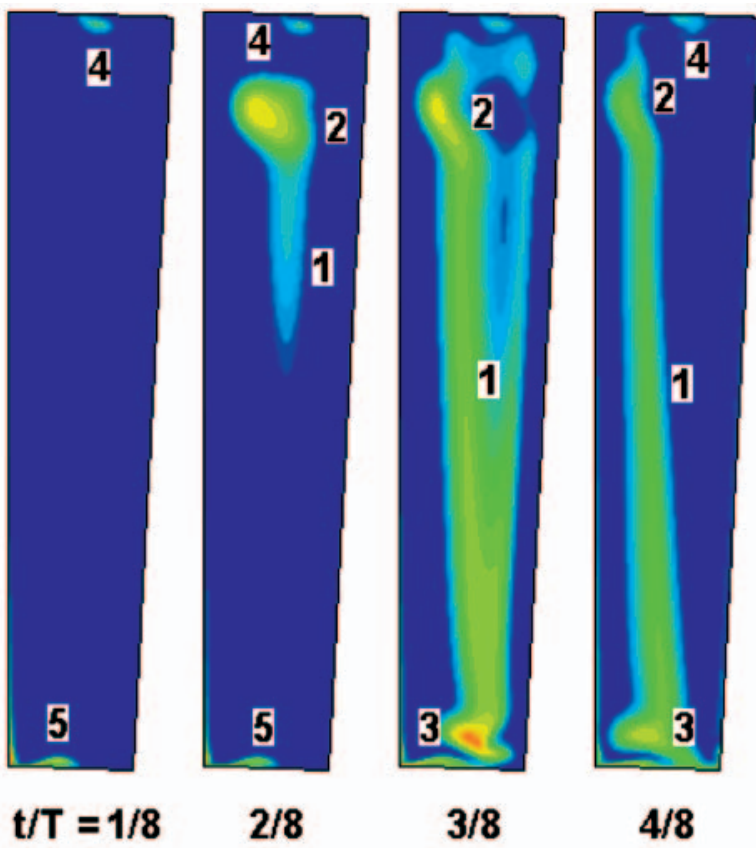

2/8

$3 / 8$
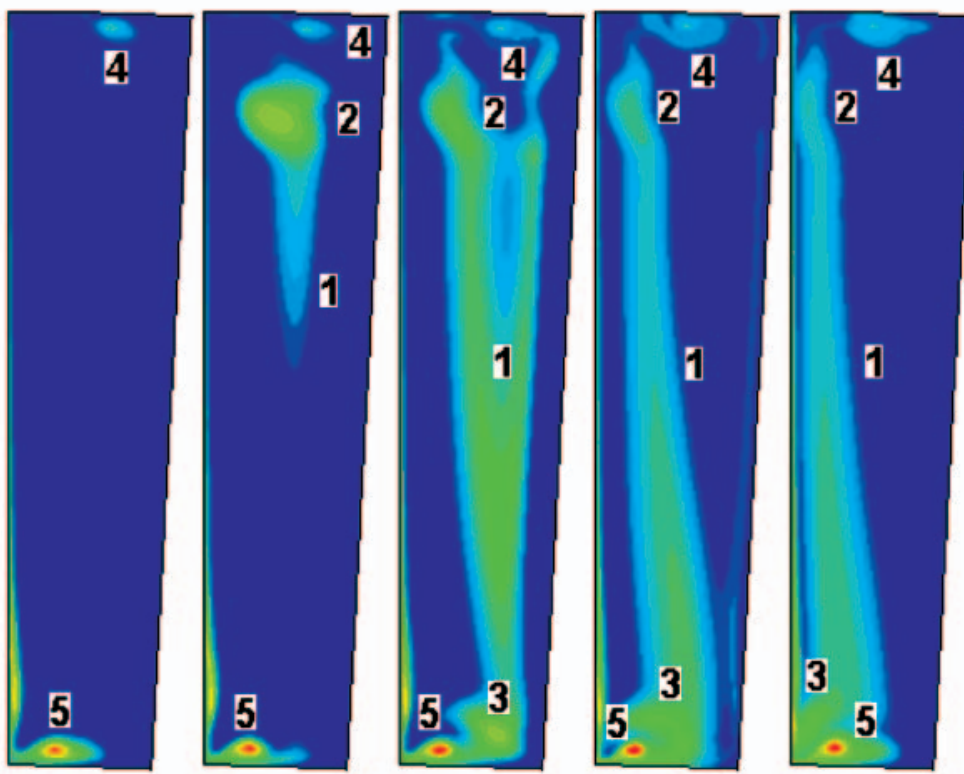
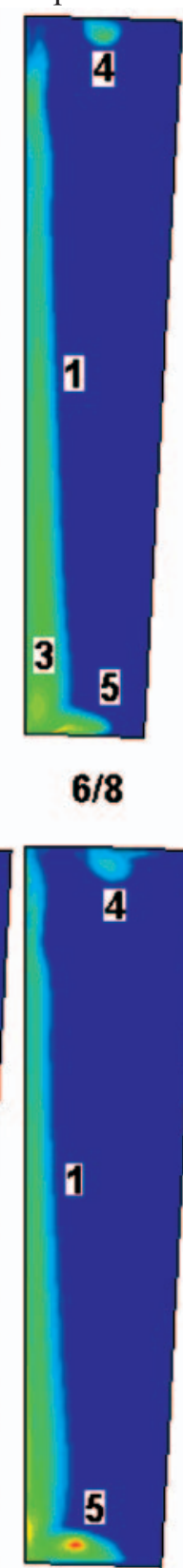

$6 / 8$

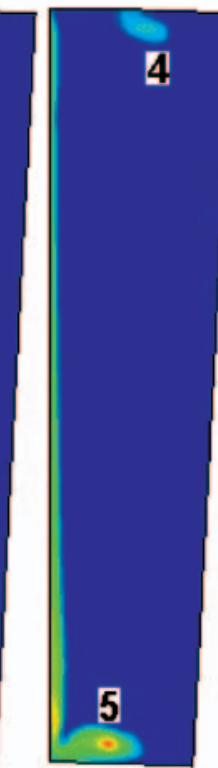

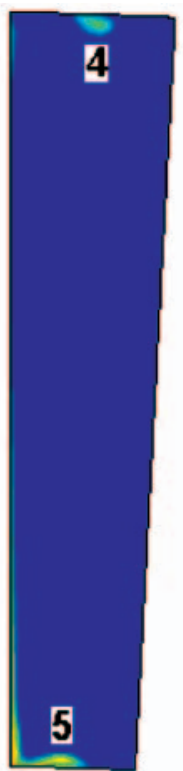

$8 / 8$

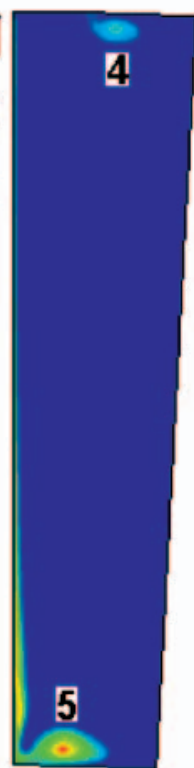

Fig. 6. Flow patterns in inlet rotor passage plane, $z / c=0.3$ : top - REF stage, bottom - LES stage 


\section{Inlet plane, $z / c=0.3$}

The flow patterns recorded in this plane are shown in Fig. 6. The main effect shown here is the passing of the stator wake (1) with the stator passage vortices (2) and (3), presented in figures $\mathrm{t} / \mathrm{T}=2 / 8$ to $6 / 8$. Moreover, some traces of two rotor horseshoe vortices (4) and (5), one vortex at the hub endwall and one at the tip endwall, can bee seen in each figure. The next figure, Fig. 7, gives a closer look at these structures, observed in the REF rotor when they are not disturbed by the stator vortices. In these conditions the tip horseshoe vortex has a regular shape and generates a velocity field typical for well developed vortices. At the same time the shape of the hub horseshoe vortex is less regular and more ellipsoidal, which is believed to be provoked by the passage cross flow, the action of which leads to the formation of the rotor passage vortex downstream in the rotor. This observation seems to be confirmed by the presence of an irregular high entropy area in the vicinity of the lower part of the rotor blade, on its suction side. The horseshoe vortices formed in the LES stage, as compared to the REF stage, are more intensive and seem to reveal more dramatic changes concerning both their strengths and locations. Also the area of initial formation of the passage vortex is much more remarkable.

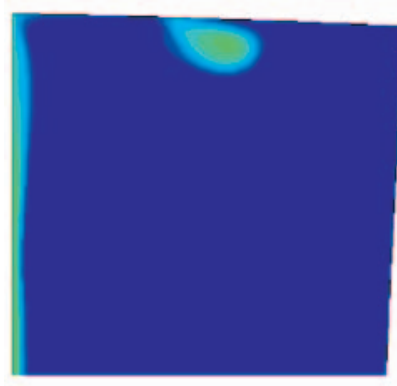

Entropy

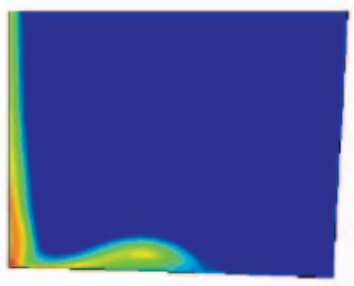

Fig. 7. Horseshoe vortices forming at tip and hub endwalls. $R E F$ rotor, $z / c=0.3$, flow without stator disturbances

Since both the tip and hub horseshoe vortices are located close to their endwalls, most remarkable effects which they provoke can be observed in these regions. Therefore a reasonable approach in these circumstances seems to be studying the interaction of these vortices with the stator structures via analysing changes of flow parameters along the tip and hub endwalls. Fig. 8 shows the distributions of circumferential velocity along the rotor endwalls in the REF and LES stages. In the diagrams presented in the figure, full marks represent times $\mathrm{t} / \mathrm{T}=2 / 8 \div 5 / 8$ during which the stator structures pass the plane $\mathrm{z} / \mathrm{c}=0.3$, while the empty marks are used for more distant times.

An important factor affecting the interaction of the horseshoe vortices with the oncoming stator wakes is the relation between strengths of particular structures. In the REF rotor the horseshoe vortices are much weaker than their equivalents in the LES rotor. As a consequence, they are much more vulnerable to the action of the stator structures. For instance, changes of peak velocities generated by the tip vortex at its endwall during the interaction with the stator wake amount to about $22 \mathrm{~m} / \mathrm{s}(69 \%$ of the average peak value) and $10 \mathrm{~m} / \mathrm{s}(16 \%$ of the average peak value) for the REF stage and LES stage, respectively. The weak hub horseshoe vortex in the REF rotor is the reason why the velocity distributions generated by this vortex in combination with the oncoming wakes reveal visibly different shapes, while those observed in the LES rotor are much more regular. On the other hand, location changes of both the tip vortex and the hub vortex, measured as deflections of peak velocity position from its average reference, are larger in the LES stage. But flow analyses performed in steady-state mode, in which the action of the stator structures was neglected, have revealed that the observed oscillations of horseshoe vortex locations in the LES stage result from their strength, and are not the effect of interaction with the stator wake.
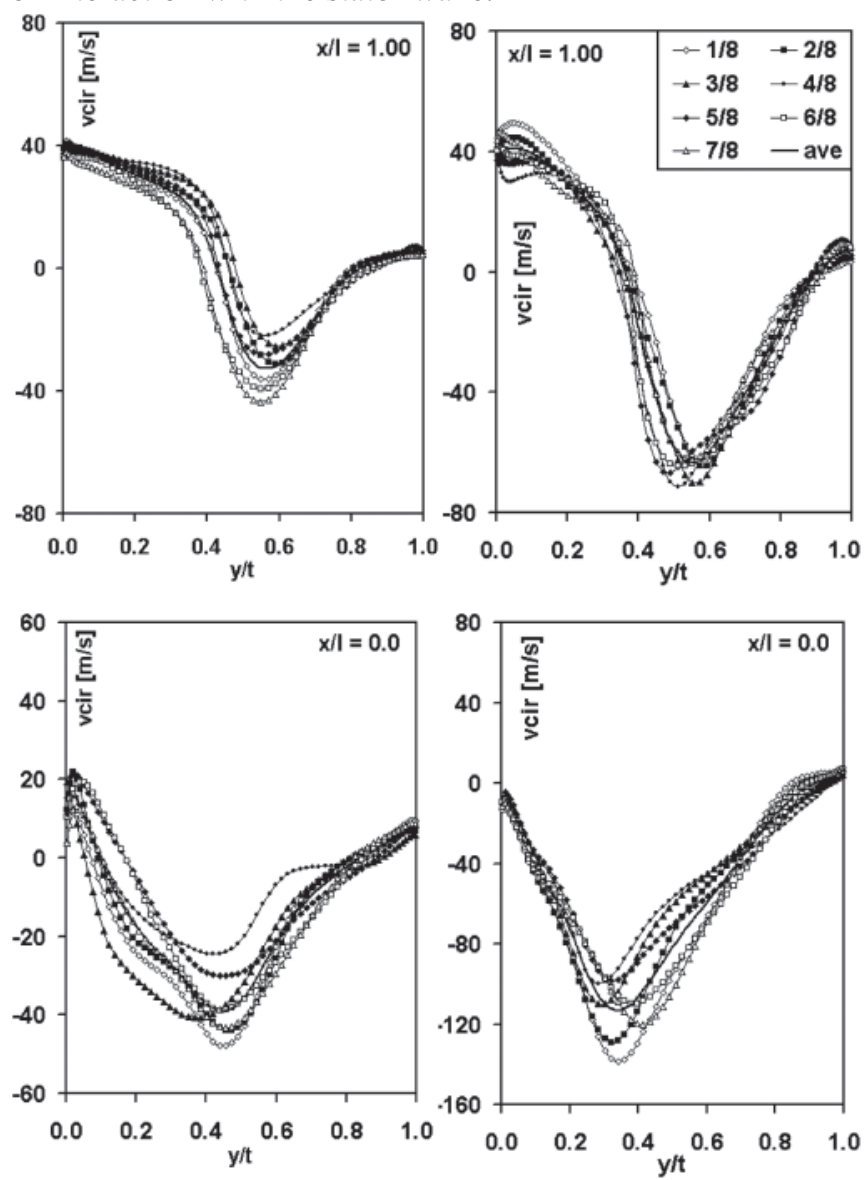

Fig. 8. Circumferential velocity distributions along tip endwall (up) and hub endwall (down) of the REF rotor (left) and the LES rotor (right)

\section{Exit plane, $z / c=0.9$}

The flow patterns recorded in this plane are shown in Fig. 9. The main effects of stator wake passing are shown in figures $\mathrm{t} / \mathrm{T}=2 / 8$ to $7 / 8$. Some traces of the tip horseshoe vortex (4), can bee recognised in each figure near the tip endwall.

A new structure, better recognisable in the upper series, is a passage vortex (5) located close to the suction side of the rotor blade, near the hub endwall. A magnified view of this vortex is given in Fig. 10, along with the corresponding distribution of secondary velocity vectors. Also the stator wake pattern in the tip part of the rotor passage has taken a new shape suggesting the presence of vortices in there, see figures $\mathrm{t} / \mathrm{T}=3 / 8$ for instance,. A closer look at the distribution of velocity vectors in that area, see Fig. 11, makes it possible to notice three vortices. The vortex located closest to the tip endwall is the tip rotor horseshoe vortex (4), while the two 

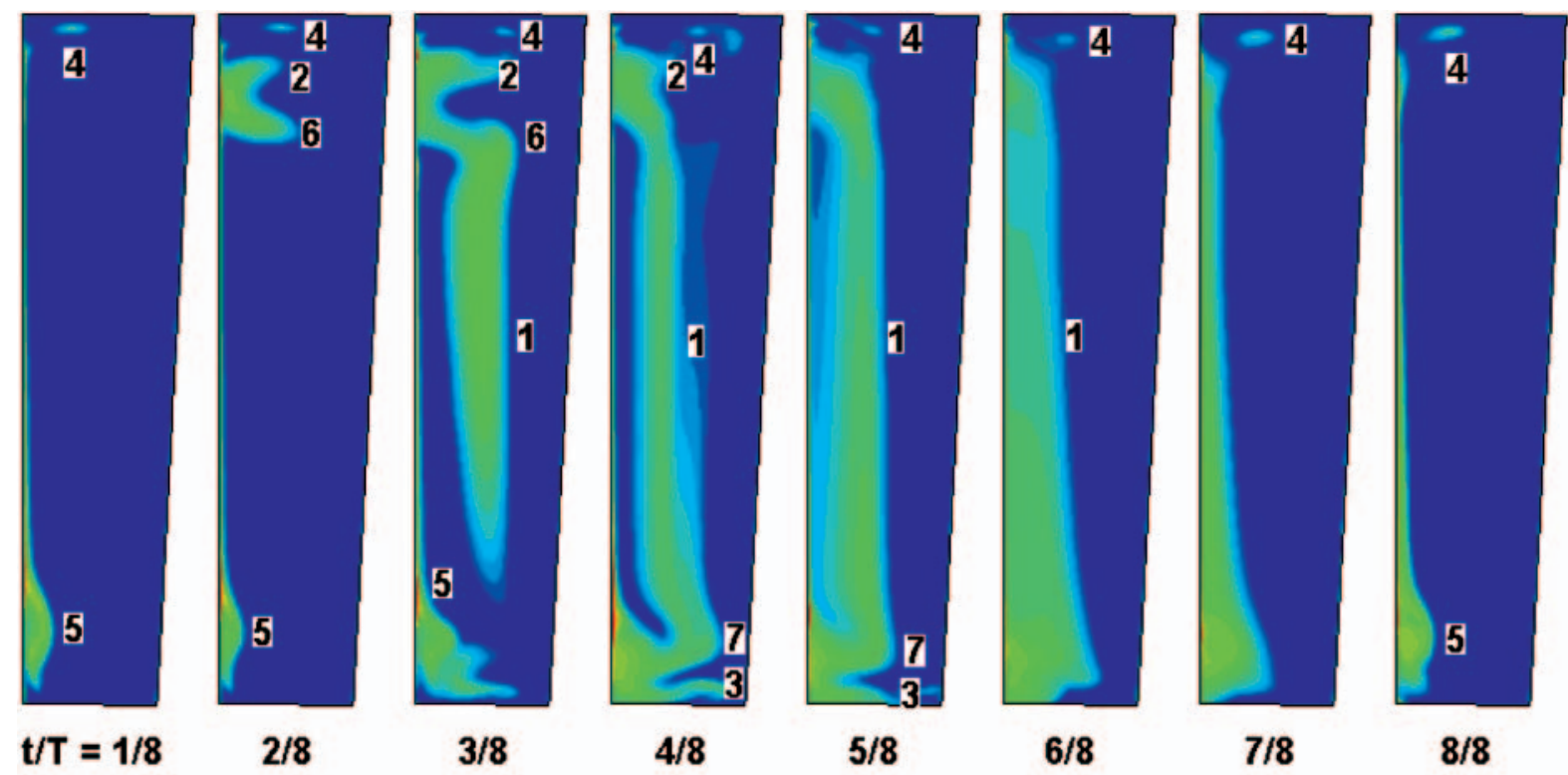

2/8
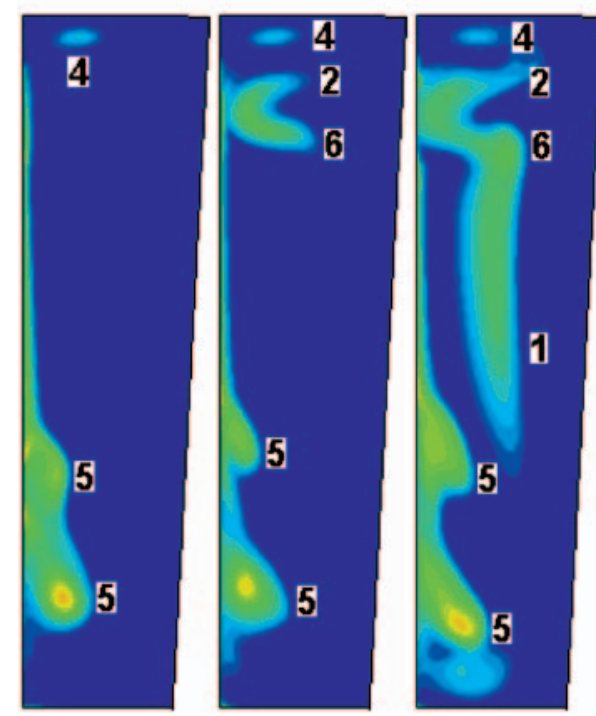

$4 / 8$

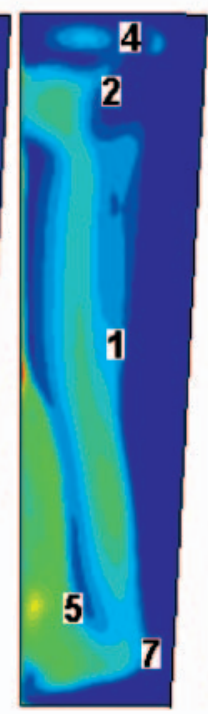

$5 / 8$
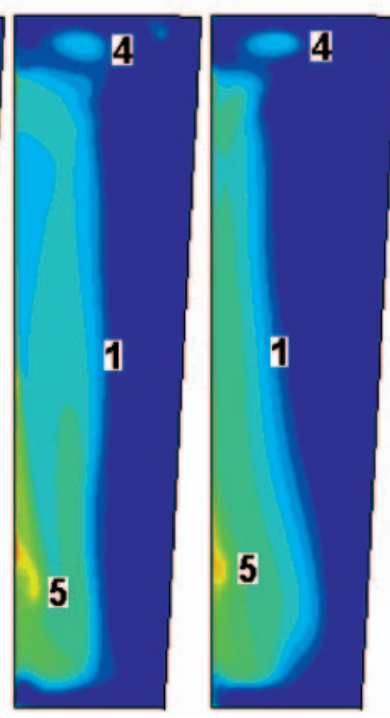

$7 / 8$
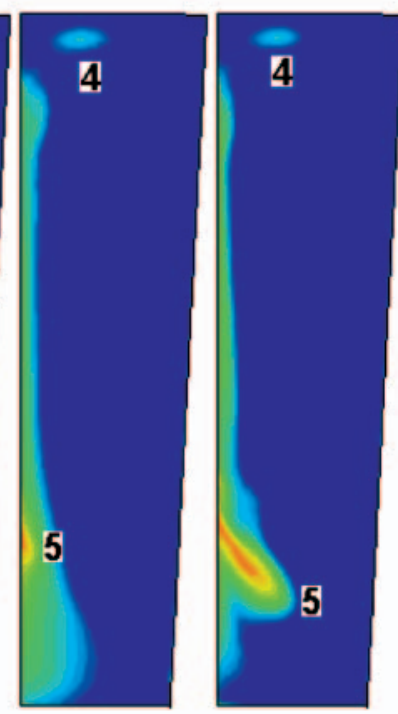

Fig. 9. Flow patterns in exit rotor passage plane, z/c =0.9: top - REF stage, bottom - LES stage

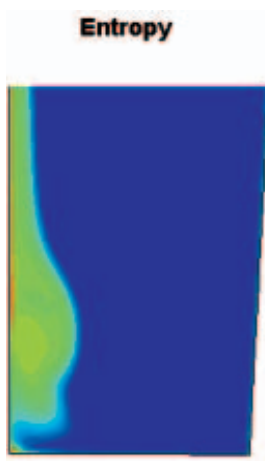

Secondary velocity vectors

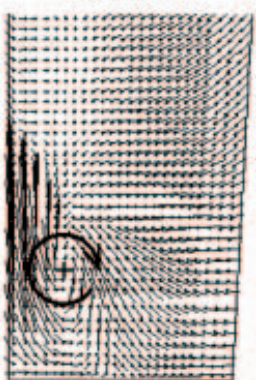

Fig. 10. Rotor passage vortex near rotor blade suction side: $R E F$ stage, $z / c=0.9$, flow without stator disturbances

remaining vortices are stator structures. Based on the analysis presented by Doerffer et al. [11], they can be recognised as the stator passage vortex (2), of clockwise rotation, and the so-called trailing shed vortex (6), of counterclockwise rotation, which forms due to the interaction of the stator passage vortex with the stator blade trailing edge. It is noteworthy that making distinction between those two structures earlier, in rotor passage sections located upstream of $\mathrm{z} / \mathrm{c}=0.9$, was very difficult due to low strength of the stator passage vortex.

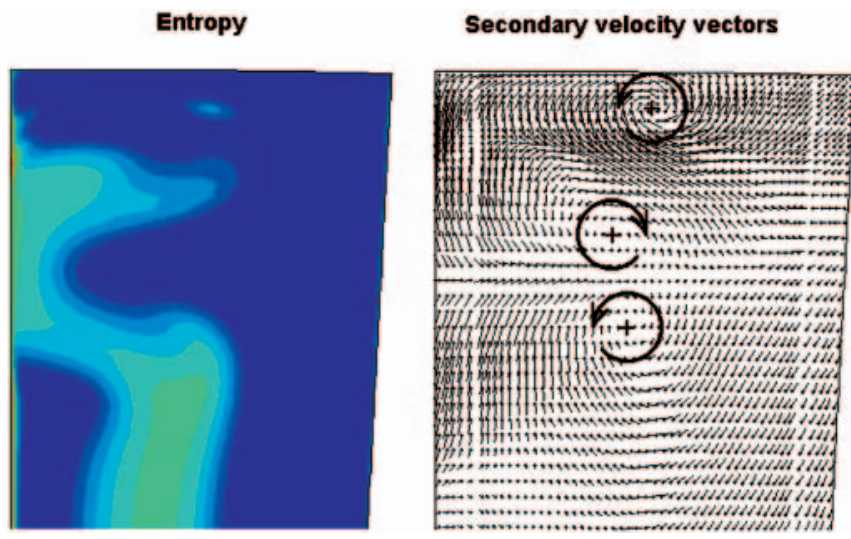

Fig. 11. Combination of vortices near rotor passage tip endwall: REF stage, $z / c=0.9$, flow at presence of stator wake

The interaction of the vortex structures in the LES rotor is much more unstable than in the REF rotor. This is especially noticeable for the rotor passage vortex (5) which in some figures breaks down into two structures. A detailed study of this phenomenon in classical steady-state conditions, when the effect of stator/rotor interaction is neglected, has revealed that in this case the process of passage vortex formation is highly unsteady and takes a cyclic course, Fig. 12, during which the 
vortex grows in intensity and moves up along the rotor blade suction side surface. At some critical point it breaks down into two minor structures, the upper of which vanishes while the lower returns to the position from which it started to gain intensity. Some traces of this behaviour can be noticed in Fig. 9, lower series, but in a rather obscure form. The process of rotor passage vortex growth starts just after the passage of the stator wake, $\mathrm{t} / \mathrm{T}=6 / 8 \div 8 / 8$, after which it quickly breaks down into two structures, $\mathrm{t} / \mathrm{T}=1 / 8 \div 3 / 8$. The time of upper vortex disappearance seems to coincide with the passage of the stator wake. In general, the origin of the entire phenomenon is the flow separation in the vicinity of the rotor blade trailing edge, and the role of the stator wake is to impose more regular periodicity to its course rather than to initiate it.

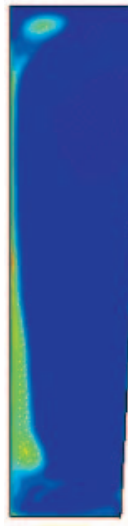

7000

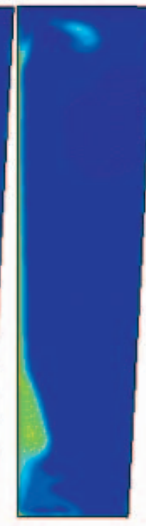

8000

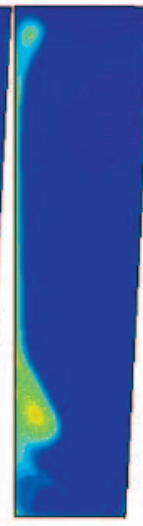

9000

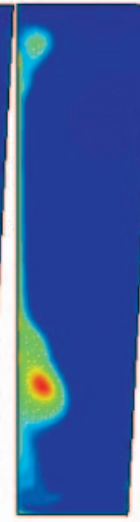

10000

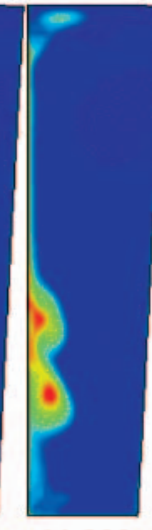

11000

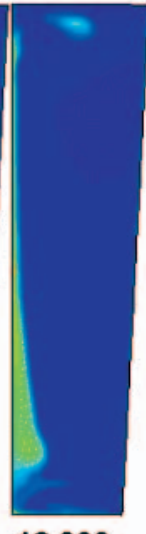

12000
Fig. 12. Passage vortex formation in the LES rotor in steady-state conditions

The unsteady phenomena in this plane occupy more passage area than for the plane $\mathrm{z} / \mathrm{c}=0.3$, therefore of better use seems to be analysing the flow field at blade surfaces rather than near the endwalls. Fig. 13 shows spanwise distributions of radial velocity fluctuations at the rotor blade suction side. For the REF stage, practically no radial velocity is observed along the central part of the blade, $x / 1=0.3 \div 0.7$. In the tip section the most intensive and regular fluctuations, with three clearly noticeable local extrema, are observed for the time $\mathrm{t} / \mathrm{T}=3 / 8$, i.e. for the configuration of vortices shown in Fig. 11. In the hub section, on the other hand, the most intensive fluctuations are those recorded for $\mathrm{t} / \mathrm{T}=1 / 8 \div 3 / 8$, i.e. when the stator wake is relatively distant from the rotor blade suction side. This effect can be interpreted as generated by the rotor passage vortex alone, and cancelled in most part when the rotor passage vortex comes into the interaction with the stator wake.

In the LES stage intensive velocity fluctuations are observed in the entire bottom half of the rotor passage. Their actual distribution seems to be dominated by the state and location of the rotor passage vortex (or vortices), with minor and poorly defined contribution of the passing stator wake. In the tip section the general pattern of velocity fluctuations is similar to that observed in the REF stage, with the only quantitative differences resulting from different relative strengths of the stator and rotor structures.

\section{Free-stream vortex interaction, $z / c=1.1$}

The flow patterns recorded in this plane are shown in Fig. 14. Like in previous planes, the vortex interaction in the REF stage takes a relatively regular course. The rotor wake (8), shown near the right-hand side of each figure, is thin, sharp and regular over most of its length, with recognisable traces of the rotor passage vortex (5) and the trailing shed vortex (9). The stator wake moves next to the rotor wake on its right, which is a tendency already known from two-dimensional analyses. Only the lower part of the stator wake structure, in the area where the stator hub passage vortex (3) is located, is shifted towards the other side of the rotor wake, $t / T=4 / 8$. The interaction of the stator and rotor wakes does not produce visible effects along their regular fragments, $\mathrm{x} / \mathrm{l}=0.3 \div 0.7$. The only effects can be observed in the hub and tip part of the turbine passage, where the rotor wake shape and entropy distribution changes from figure to figure.

The stator/rotor wake interaction in the LES stage is much more unstable and irregular. The rotor wake (8), this time located on the left-hand side of the each figure, is accompanied by a number of additional vortices in its lower part, a possible effect of the rotor passage vortex breakdown. The lower part of the passage vortex (5), which in plane $\mathrm{z} / \mathrm{c}=0.9$ was a single structure, now has a form of a vortex pair, $\mathrm{t} / \mathrm{T}=3 / 8 \div 4 / 8$. A possible mechanism which generates the additional vortex to compose the vortex pair seems to be the same as that which leads to the production of the trailing shed vortex by the passage vortex, i.e. velocity field disturbances induced at the blade trailing edge by the primary structure.

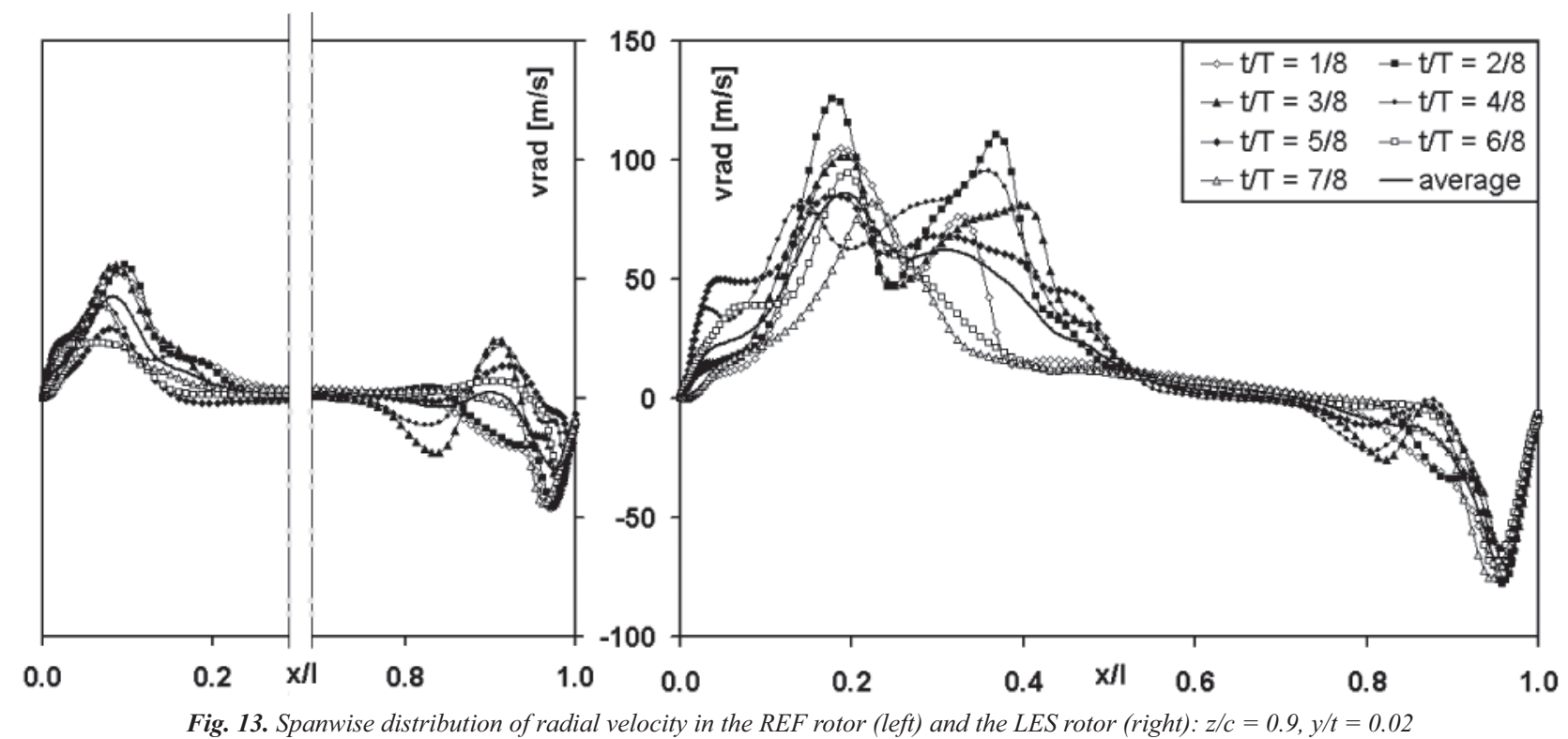



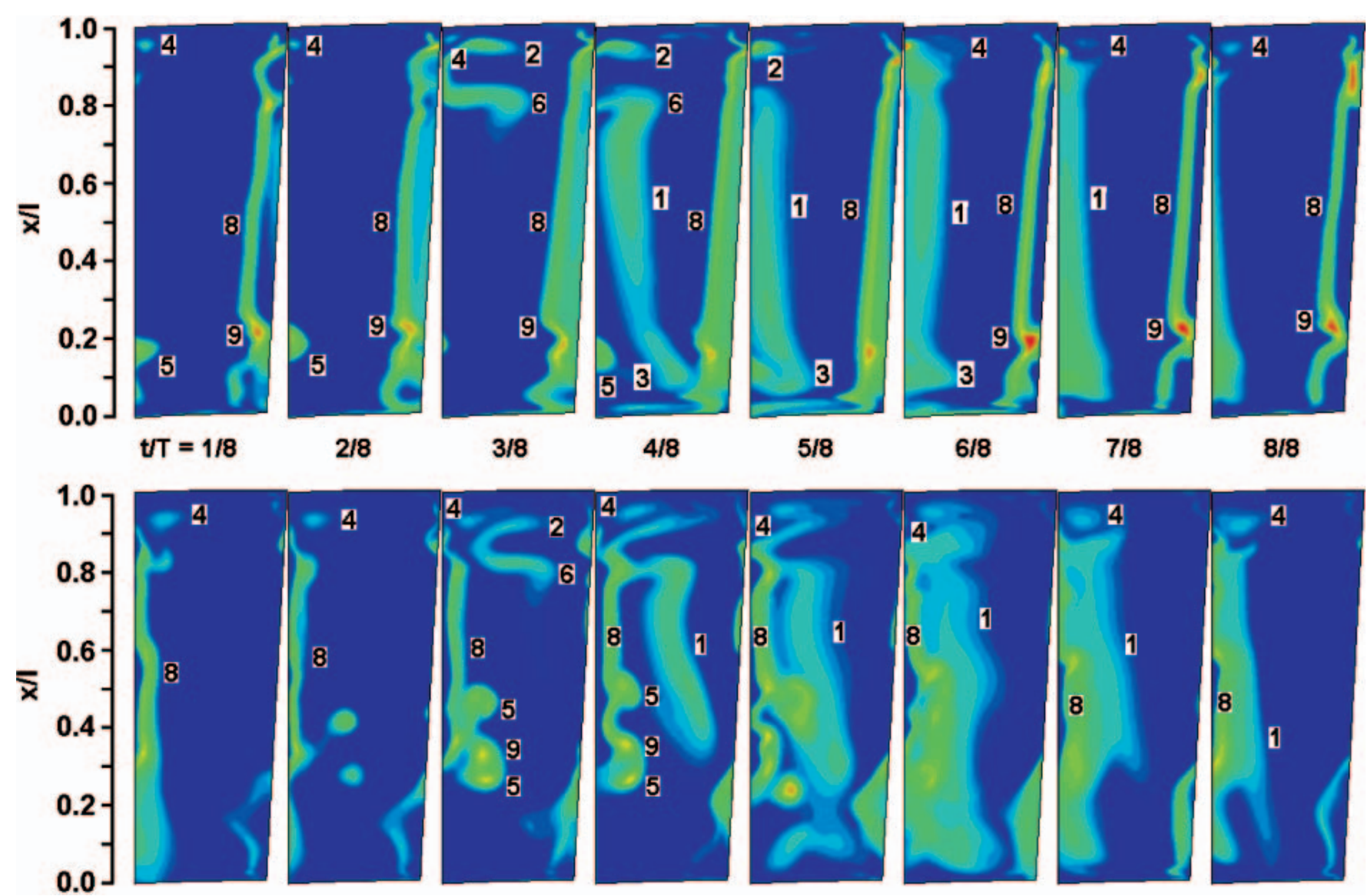

Fig. 14. Free-stream vortex interaction downstream of the rotor, z/c $=1.1:$ top - REF stage, bottom - LES stage
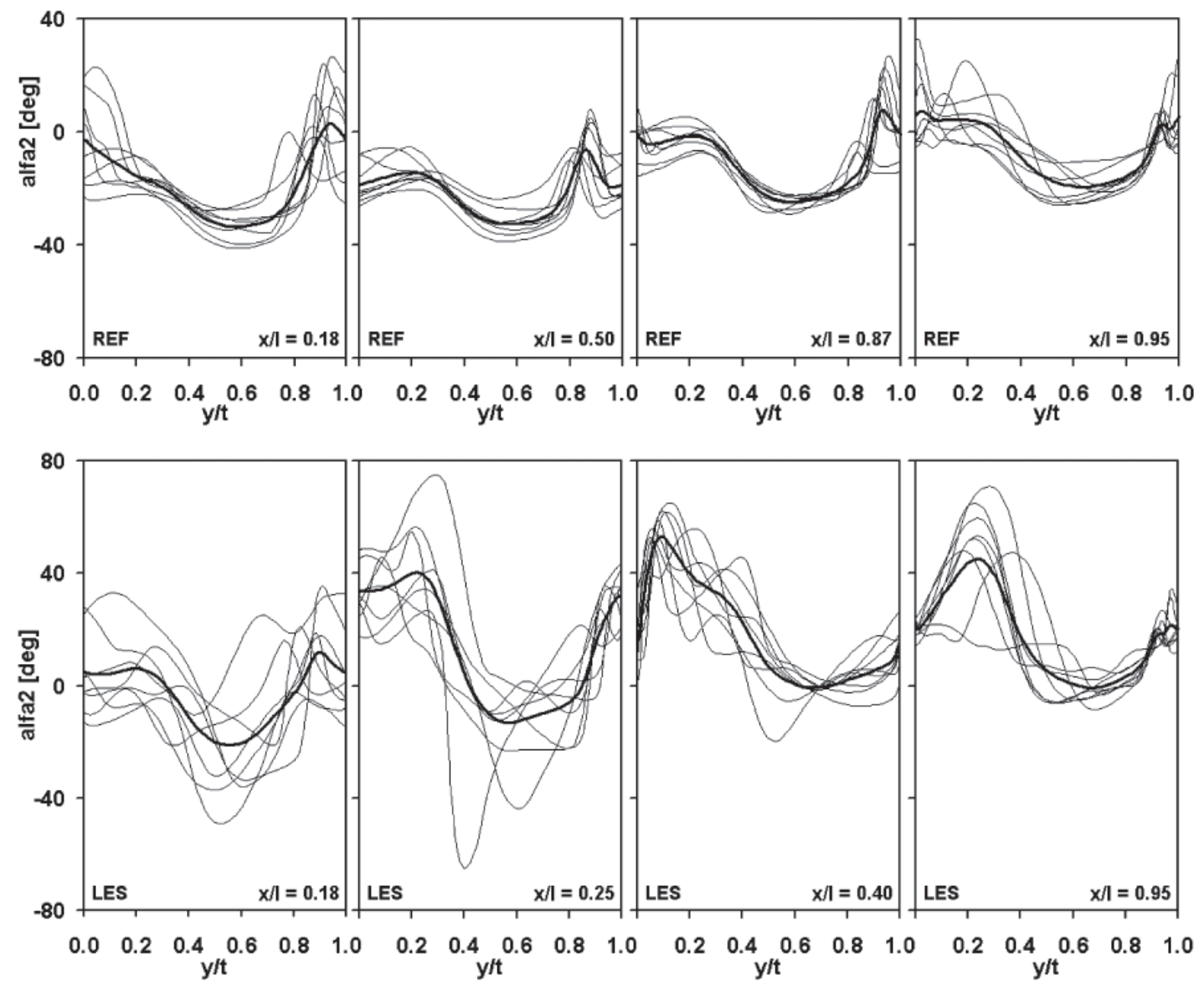

Fig. 15. Absolute flow angles at rotor exit, z/c =1.1: top - REF stage, bottom - LES stage 
The measurable effects of vortex interaction in the examined plane are shown in Fig. 15, in the form of distributions of absolute flow angles (measured from the axial direction) in selected traverses $\mathrm{x} / \mathrm{l}=$ const. Thin curves in the figure represent individual realisations, while the thick one is their average. In the upper series, for the REF stage, the effect of the stator/rotor wake interaction can be observed as: (a) changes in the intensity and location of the peak on the right, which represents the rotor wake, and (b) flow angle fluctuations observed close to the lefthand part of the diagram and provoked directly by the passing stator wake. Both types of disturbances are the highest for the extreme $\mathrm{x} / \mathrm{l}$ values: $\mathrm{x} / \mathrm{l}=0.18$ and 0.95 , but even in those cases they do not diverge by more that 25 degrees from corresponding average local values. In the LES stage flow angle fluctuations are much more intensive and irregular, and in extreme cases can reach over 70 degrees, $\mathrm{x} / \mathrm{l}=0.25, \mathrm{y} / \mathrm{t}=0.4$.

\section{CONCLUSIONS}

The paper presents an analysis of the three-dimensional interaction of vortex structures in a turbine rotor. Two high-pressure steam turbine stages were selected as representative for the examination: the standard (REF) stage which revealed regular performance characteristics and distributions of flow parameters, and the low-efficiency (LES) stage in which a separation zone was observed in the rear part of the rotor passage. In the REF rotor the passing stator structures provoke noticeable changes in instantaneous strengths and locations of the horseshoe and passage vortices forming in the rotor passage area. In the LES stage, on the other hand, where the rotor vortices are much more intensive and unstable, they are the main source of flow unsteadiness, only slightly affected by the passing stator wakes the role of which is to in to introduce some regularity in the development of the rotor structures.

The information on the presented two interaction patterns contributes to better understanding of unsteady phenomena taking place in turbine rotors, and is believed to be applicable for a variety of turbine stage constructions with radial blades. In large stationary turbine stages, with well designed profiles and optimised stage operation conditions, the pattern referred to as REF in the article is believed to be representative for the vortex interaction. At the same time for smaller turbines of both land and marine applications, where certain technological limitations make it impossible for the stage design to follow all flow requirements and the resultant stage operation efficiency is relatively low, the vortex interaction pattern close to that here referred to as LES is likely to be observed.

\section{BIBLIOGRAPHY}

1. Goldstein R.J., Spores R.A.: Turbulent transport on the endwall in the region between adjacent turbine blades, Trans. ASME, J. Heat Transfer, vol. 110, 1988

2. Doerffer P., Amecke J.: Secondary flow control and stream-wise vortices formation, ASME Paper. 94-GT-376, 1994

3. Wang H.P., Olson S.J., Goldstein R.J., Eckert E.R.G.: Flow visualization of a linear turbine cascade of high performance turbine blades, J. Fluid Mech., vol. 134, 1997

4. Swirydczuk J.: Grid resolution in numeric analyses of stator/rotor interactions (in Polish), SYSTEMS Journal of Transdisciplinary Systems Science, vol. 11, 2006

5. Lardeau, S., Leschziner, M.A. : Unsteady RANS modelling of wake-blade interaction: computational requirements and limitations", Computers \& Fluids, vol. 34, 2005

6. Yershov, S., Rusanov, A., Gardzilewicz, A., Lampart, P., Swirydczuk, J.: Numerical Simulation of $3 D$ Flow in Axial Turbomachines, TASK Quarterly, vol. 2, 1998

7. Lampart P. , Swirydczuk J., Gardzilewicz A.: On the prediction of flow patterns and losses in an HP axial turbine stages using $3 D$ RANS solver with two turbulence models, TASK Quarterly vol. 5,2001

8. Lampart P., Rusanov A., Yershov S., Marcinkowski S., Gardzilewicz A.: Validation of a 3D RANS Solver With a State Equation of Thermally Perfect and Calorically Imperfect Gas on a Multi-Stage Low-Pressure Steam Turbine Flow, ASME J. Fluids Engineering, vol. 127, 2005

9. Swirydczuk J.: Vortex Dynamics of the Stator Wake-Rotor Cascade Interaction, ASME J. Fluids Engineering, vol. 124, 2002

10.Kost F., Hummel F., Tiedemann M.: Investigation of the Unsteady Rotor Flow Field in a Single HP Turbine Stage, Proc. ASME TURBO EXPO 2000, May 8-11, Munich, Germany, 2000

11.Doerffer P., Rachwalski J., Magagnato F.: Numerical Investigation of the Secondary Flow Development in Turbine Cascade, TASK Quarterly, vol. 5, 2001.

\section{CONTACT WITH THE AUTHOR}

Jerzy Świrydczuk, Assoc. Prof. Institute of Fluid-Flow Machinery Fiszera 14 80-952 Gdansk, POLAND e-mail: jsk@imp.gda.pl 